\title{
Serum Hepcidin Is Increased in ANCA-Associated Vasculitis and Correlates With Activity Markers
}

\section{P. PŘIKRYL ${ }^{1}$, Z. HRUŠKOVÁ ${ }^{2}$, P. KONOPÁSEK ${ }^{2}$, Z. HLADINOVÁ ${ }^{2}$, V. TESAŘ $\check{R}^{2}$, M. VOKURKA ${ }^{1}$}

${ }^{1}$ Institute of Pathophysiology, First Faculty of Medicine, Charles University, Prague, Czech Republic, ${ }^{2}$ Department of Nephrology, First Faculty of Medicine, Charles University and General University Hospital, Prague, Czech Republic

Received September 22, 2017

Accepted June 26, 2018

On-line September 11, 2018

\section{Summary}

Hepcidin is a key regulator of iron metabolism and plays an important role in many pathologies. It is increased by iron administration and by inflammation, while erythropoiesis downregulates its expression. It decreases iron availability and thus contributes to anemia of chronic diseases. The aim of the study was to measure hepcidin as a marker and pathogenetic factor in ANCA-associated vasculitis (AAV). Hepcidin plasma concentration was measured by the immunological method in 59 patients with $\mathrm{AAV}$ and compared to patients with non-vasculitic etiology of chronic kidney disease, patients on hemodialysis (HD), with systemic lupus erythematodes (SLE) and to healthy controls and blood donors, and was correlated with the parameters of iron metabolism, inflammation, activity of the process and kidney function. Hepcidin concentration was increased in patients with $A A V$, SLE and HD and correlated positively with C-reactive protein, serum ferritin and creatinine, and negatively with hemoglobin and serum transferrin. In active form of AAV it correlated with the clinical scoring system (BVAS). Hepcidin can thus be considered as a pathogenetic factor of anemia in AAV and can be used for evaluation of inflammation in $A A V$ and as an additional marker in active forms of the disease.

\section{Key words}

Hepcidin • Iron • Anemia • Inflammation • ANCA

\section{Corresponding authors}

M. Vokurka, Institute of Pathological Physiology, First Faculty of Medicine, Charles University, U Nemocnice 5, 12853 Prague, Czech Republic. E-mail: martin.vokurka@LF1.cuni.cz and
V. Tesar, Department of Nephrology, First Faculty of Medicine, Charles University and General University Hospital, U Nemocnice 2, 12808 Prague, Czech Republic. E-mail: vladimir.tesar@LF1.cuni.cz

\section{Introduction}

Hepcidin is a key regulator of systemic iron metabolism as reviewed by Arezes and Nemeth (2015). It decreases iron absorption in the duodenum and iron release from macrophages, thus controlling iron stores and iron plasmatic concentration. It is a 25 amino acid peptide produced mainly in the liver and its active form is cleaved from a larger precursor called prohepcidin. In the urine 20,22 and 24 amino acid variants can be also detected with an unclear role (Kemna et al. 2007, Laarakkers et al. 2013). Hepcidin expression is controlled by iron, erythropoiesis and inflammation (Nemeth et al. 2003, Vokurka et al. 2006). The mechanisms of hepcidin regulation have been partially described at molecular levels (Rishi et al. 2015). It is upregulated by interleukin-6 (IL-6) and it is considered as a type II acutephase protein (Nemeth et al. 2003). Increased hepcidin concentration contributes to functional iron deficiency and is thus involved in ACD pathogenesis (Wang and Babitt 2016). Hepcidin is detected by mass spectrometry or by immunological methods. The former brings information about various isoforms of hepcidin but is technically challenging (Addo et al. 2016, Kemna et al. 2007), the latter can be used for routine clinical measurements and studies. 
The measurement of hepcidin is of interest in many clinical situations where it could serve as a biomarker, like inflammatory conditions (Casper et al. 2015), iron-related disorders (Drakesmith 2016), diseases combining these conditions (Honda et al. 2016) and surgery (Maruna et al. 2011). In inflammatory diseases, it can be used as a marker of activity as already illustrated in the urine (Zhang et al. 2008, Zhang et al. 2012) or in the serum (Indrakanti et al. 2017) of patients with lupus nephritis. The published results are not unequivocal. Apart from its production, hepcidin concentration in the plasma depends also on its degradation or renal clearance (Troutt et al. 2013) and hepcidin has been studied in chronic kidney disease (CKD) (Ganz and Nemeth 2016, Macdougall et al. 2010).

Antineutrophil cytoplasmic antibody (ANCA)associated vasculitides (AAVs) are a group of inflammatory vascular diseases, belonging among small vessel vasculitides characterized namely by the involvement of ear, nose and throat (ENT), lungs and the kidneys (Talarico et al. 2013, Tesar and Hruskova 2013). AAV are characterized by the association of antineutrophil cytoplasmic antibodies directed to proteinase 3 (PR3-ANCA) or myeloperoxidase (MPO-ANCA) are strongly associated with AAVs (Kallenberg 2010) and seem to play an important role in the pathogenesis of vascular damage in patients with AAV (Gomez-Puerta et al. 2009). The course of the disease is strictly individual, but often presenting as a multisystem disorder. It may be life threatening if there is a major organ involvement, such as of lungs or kidneys which can lead to the renal failure (Hamour et al. 2010).

Most patients with active renal AAV present with increased C-reactive protein (CRP), decreased renal function and mild to moderate anemia which may be a combination of anemia of chronic diseases (ACD) and renal anemia. There is a need for new biomarkers which would reflect these changes and could improve the non-invasive diagnostics, the assessment of the activity of the disease and monitoring of the treatment efficacy.

Whereas renal anemia is caused by an impaired production of erythropoietin, the pathogenesis of ACD includes both direct and indirect effect of proinflammatory cytokines on erythropoiesis and derangement of iron metabolism (Weiss 2009). Iron is sequestrated in macrophages and this functional iron deficiency impairs red blood cell production.

So far, no data have been published on hepcidin in AAV which are typically characterized by the combination of inflammation, impaired renal function and some degree of anemia. The purpose of this study was to measure serum hepcidin and evaluate its possible pathogenetic role and diagnostic value in patients with AAV as a marker of active disease and inflammation. We compared patients with AAV with patients with other chronic kidney diseases (CKD), end stage renal disease (ESRD) on hemodialysis (HD), with systemic lupus erythematodes (SLE) and with age-matched healthy controls and blood donors (BD).

\section{Materials and Methods}

\section{Patients and control subjects}

192 subjects were involved in the study. All participants signed the informed consent and the study was approved by the local ethics committee and conducted according to the guidelines of the Helsinki Declaration. 59 patients had AAV (29 with active disease, 30 in remission), 29 patients SLE and lupus nephritis (17 patients had active disease, 12 patients were in remission of the disease, mild to moderate impairment of renal function was present in 25 out of these 29 patients).

Disease activity in AAV was assessed using the BVAS (Birmingham Vasculitis Activity Score), and BVAS $=0$ was defined as remission. In SLE and patients with lupus nephritis remission was characterized by proteinuria less than $1 \mathrm{~g} / 24 \mathrm{~h}$ and absence of extrarenal activity of the disease. Groups of patients with active disease involved both patients with the first manifestation of the disease and patients with relapse of the disease.

Among 37 patients with CKD of non-vasculitis etiology there were 21 patients with IgA nephropathy, 10 patients with autosomal dominant polycystic kidney disease and 6 patients with chronic glomerulonephritis. 21 patients had ESRD and required hemodialysis treatment (causes of ESRD differed, the most frequent diagnoses included $4 \times$ hypertensive nephropathy, $4 \times$ diabetic nephropathy, $4 \times$ chronic tubulointerstitial nephritis, $2 \times$ IgA nephropathy and $2 \times$ AAV). We used 14 healthy controls and 32 healthy blood donors as negative controls. Patients with acute infections and other diseases which could result in iron metabolism disturbances were excluded from the study.

\section{Laboratory analysis}

Blood and urine were taken by routine methods in the hospital and analyzed in the routine laboratory, 
samples for hepcidin measurement were centrifuged at $3,000 \mathrm{~g} \times 10 \mathrm{~min}$, and the supernatant was stored at $-80{ }^{\circ} \mathrm{C}$.

\section{Hepcidin determination}

Serum hepcidin-25 was determined with a commercially available ELISA kit (Bachem S-1337 EIA) according to the manufacturer's recommended protocol using the HydroFlex microplate washer and Sunrise microplate reader (Tecan). All samples were diluted to be within the concentration range of the calibration curve. Measurements were made in duplicates.

\section{Statistical analysis}

Normality was tested by d'Agostino-Pearson test. The differences were calculated by Kruskal-Wallis test followed by Dunn's multiple comparison test or Mann-Whitney test or t-test if values had normal distribution. Correlation was assessed by Spearman rank correlation. All statistical analyses were performed using GraphPad Prism 4. Data are expressed as mean \pm standard deviation (SD). $P<0.05$ values were considered statistically significant.

\section{Results}

Laboratory, inflammatory and iron metabolism parameters in the study population

The laboratory parameters of studied subjects are shown in Table 1.

Patients with AAV, SLE and HD patients had distinct anemia. This anemia showed signs of ACD as the patients had significantly higher serum ferritin level and lower serum transferrin concentration compared to the controls. However, CRP was significantly increased only in patients with AAV and SLE. Blood donors were not anemic, however, their iron metabolism parameters showed signs of iron deficiency but only serum iron and transferrin saturation (TSAT) were significantly lower than in the control group. Renal function assessed by the MDRD equation and S-creatinine was significantly impaired not only in HD patients, but also in patients with AAV and CKD. Proteinuria was significantly higher in all groups except of the control group and blood donors.

\section{Hepcidin serum concentration}

Hepcidin serum concentration was significantly higher in AAV compared to controls, blood donors and

Table 1. Patient characteristics.

\begin{tabular}{|c|c|c|c|c|c|c|}
\hline & $\begin{array}{l}\text { Control } \\
\text { group } \\
\text { (CTRL) }\end{array}$ & $\begin{array}{c}\text { Blood } \\
\text { donors } \\
\text { (BD) }\end{array}$ & $\begin{array}{c}\text { Chronic } \\
\text { kidney } \\
\text { disease } \\
\text { (CKD) }\end{array}$ & $\begin{array}{c}\text { Hemodialysis } \\
\text { (HD) }\end{array}$ & $\begin{array}{c}\text { Systemic lupus } \\
\text { erythematodes } \\
\text { (SLE) }\end{array}$ & $\begin{array}{c}\text { ANCA- } \\
\text { associated } \\
\text { vasculitis } \\
\text { (AAV) }\end{array}$ \\
\hline Number & 14 & 32 & 37 & 21 & 29 & 59 \\
\hline Male/female & $8 / 6$ & $19 / 13$ & $25 / 12$ & $10 / 11$ & $5 / 24$ & $29 / 30$ \\
\hline Age, years & $\begin{array}{c}50.0 \pm 7.1 / \\
55.5 \pm 6.3\end{array}$ & $\begin{array}{c}54.6 \pm 6.1 / \\
51.5 \pm 1.8\end{array}$ & $\begin{array}{l}47.6 \pm 15.0 / \\
43.1 \pm 17.3\end{array}$ & $\begin{array}{c}60.9 \pm 10.5 / \\
64.6 \pm 13.2\end{array}$ & $\begin{array}{c}36.4 \pm 16.9 / \\
39.3 \pm 13.4\end{array}$ & $\begin{array}{c}58.7 \pm 12.7 / \\
63.5 \pm 11.9\end{array}$ \\
\hline Hemoglobin, g/l & $143.1 \pm 11.2$ & $144.3 \pm 9.2$ & $136.1 \pm 20.4$ & $106.2 \pm 12.8 * *$ & $111.5 \pm 17.4^{* *}$ & $110.1 \pm 20.0 * *$ \\
\hline$C R P, m g / l$ & $2.43 \pm 1.77$ & $2.09 \pm 2.22$ & $3.47 \pm 2.8$ & $7.97 \pm 11.80$ & $15.79 \pm 31.15^{* * *}$ & $17.29 \pm 34.29 * * *$ \\
\hline S-iron, $\mu \mathrm{mol} / \mathrm{l}$ & $14.0 \pm 6.0$ & $5.7 \pm 5.2 \#$ & $16.3 \pm 5.8$ & $11.0 \pm 3.6$ & $13.2 \pm 6.1$ & $14.9 \pm 7.7$ \\
\hline$S$-ferritin, $\mu g / l$ & $119 \pm 78$ & $49 \pm 38 \S$ & $137 \pm 135$ & $428 \pm 219 * * *$ & $380 \pm 395 * * *$ & $513 \pm 540 *$ \\
\hline$T S A T, \%$ & $22.5 \pm 9.1$ & $8.8 \pm 7.1 \$$ & $28.8 \pm 10.9$ & $25.3 \pm 10.3$ & $29.5 \pm 14.2$ & $34.2 \pm 20.5$ \\
\hline S-transferrin, $g / l$ & $2.74 \pm 0.17$ & $2.85 \pm 0.44 \S$ & $2.60 \pm 0.53$ & $1.94 \pm 0.31 * *$ & $1.98 \pm 0.57 * *$ & $2.03 \pm 0.57 * *$ \\
\hline S-creatinine, $\mu \mathrm{mol} / \mathrm{l}$ & $74 \pm 15$ & $83 \pm 12$ & $190 \pm 119 * * *$ & N/A & $124 \pm 78$ & $255 \pm 151 * * *$ \\
\hline$M D R D, \mathrm{ml} / \mathrm{min}$ & $88 \pm 20$ & $75 \pm 11$ & $46 \pm 28 * * *$ & $\mathrm{~N} / \mathrm{A}$ & $63 \pm 37$ & $34 \pm 30 * * *$ \\
\hline Proteinuria, g/24 h & $0.09 \pm 0.07$ & $0.19 \pm 0.67$ & $0.73 \pm 0.96 * * *$ & $\mathrm{~N} / \mathrm{A}$ & $1.41 \pm 2.03 * * *$ & $0.93 \pm 2.32 * * *$ \\
\hline
\end{tabular}

MDRD - glomerular filtration rate calculated by Modification of Diet in Renal Disease equation. Results are presented as mean \pm SD. * significant vs. CTRL, BD and patients with CKD, ** significant vs. CTRL, *** significant vS. CTRL and BD, § significant vs. HD, SLE, AAV, \# significant vs. CTRL, CKD, SLE, AAV, \$ significant vs. CTRL, CKD, HD, SLE, AAV. N/A - not assessed. Significance level is $p<0.05$. 


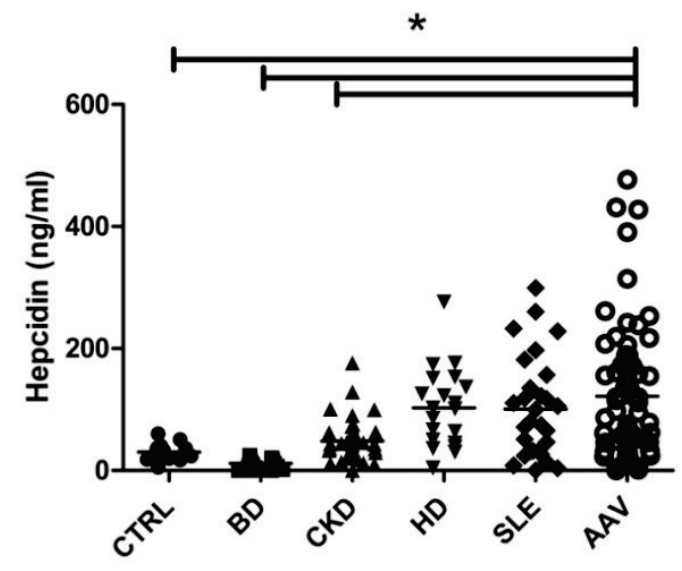

Fig. 1. Serum hepcidin concentrations. AAV - ANCA-associated vasculitis, BD - blood donors, CKD - chronic kidney disease, CTRL - control patients, HD - hemodialysis, SLE - systemic lupus erythematodes, * statistically significant $(p<0.05)$.

patients with CKD. It did not differ from the patients with SLE and HD. Hepcidin concentration in blood donors was not significantly different from controls, however, it was significantly lower compared to all other groups (Fig. 1). Hepcidin concentration did not differ between the subgroups of the patients with CKD.

Hepcidin concentration in patients with AAV, SLE and HD correlated positively with CRP, S-ferritin and S-creatinine, while it negatively correlated to hemoglobin and S-transferrin (Table 2). No significant correlation was observed for healthy controls and blood donors.

\section{Activity of the process}

AAV and SLE patients were subdivided into two groups according to the activity of the disease as described above (Table 3). When divided according to the activity of the disease, there were no differences in hepcidin concentration in AAV and SLE patients with active or quiescent disease (Fig. 2A) and hepcidin was not superior to CRP (Fig. 2B). Their separate comparison to other studied groups showed the same statistical significance as when considered together. ANCA titer was significantly increased and renal functions decreased in patients with active AAV. Other laboratory data showed significantly decreased hemoglobin, S-iron, and S-transferrin and increased proteinuria in active disease in AAV and SLE. The S-ferritin did not differ between the AAV patients in active phase and those in quiescent phase. BVAS in active disease correlated with hepcidin concentration and CRP (Figs $3 \mathrm{~A}$ and 3B) but did not correlate with ANCA titer.

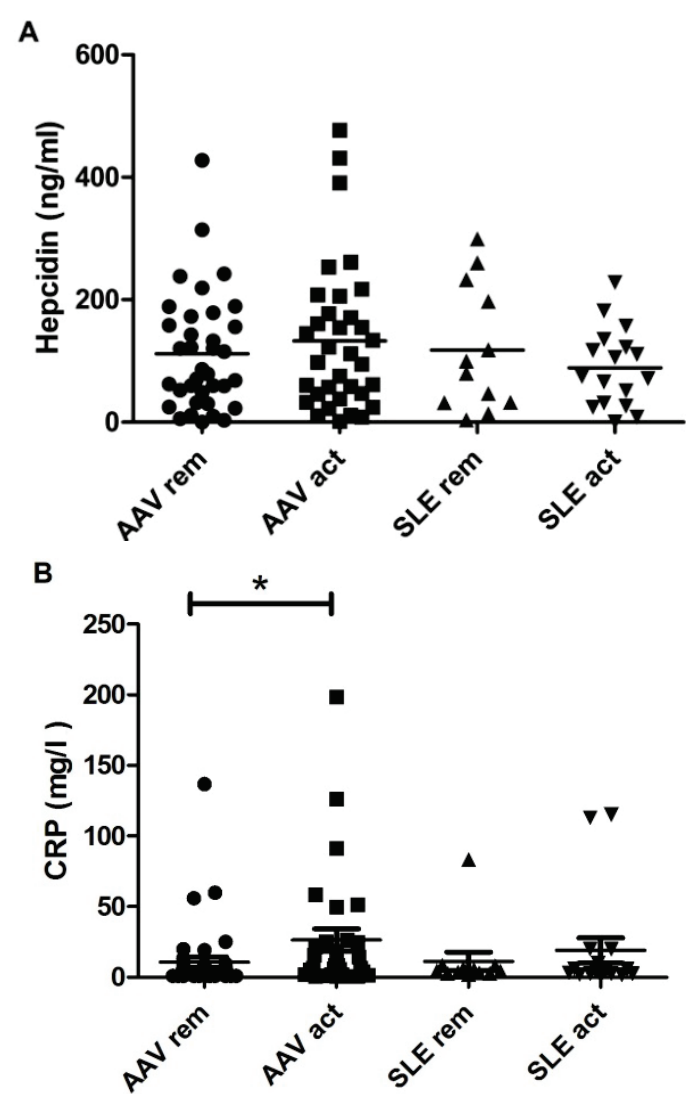

Fig. 2. Serum concentration of hepcidin (A) and C-reactive protein (B) in patients with AAV and SLE in remission (rem) and with active disease (act), * $\mathrm{p}=0.0218$.
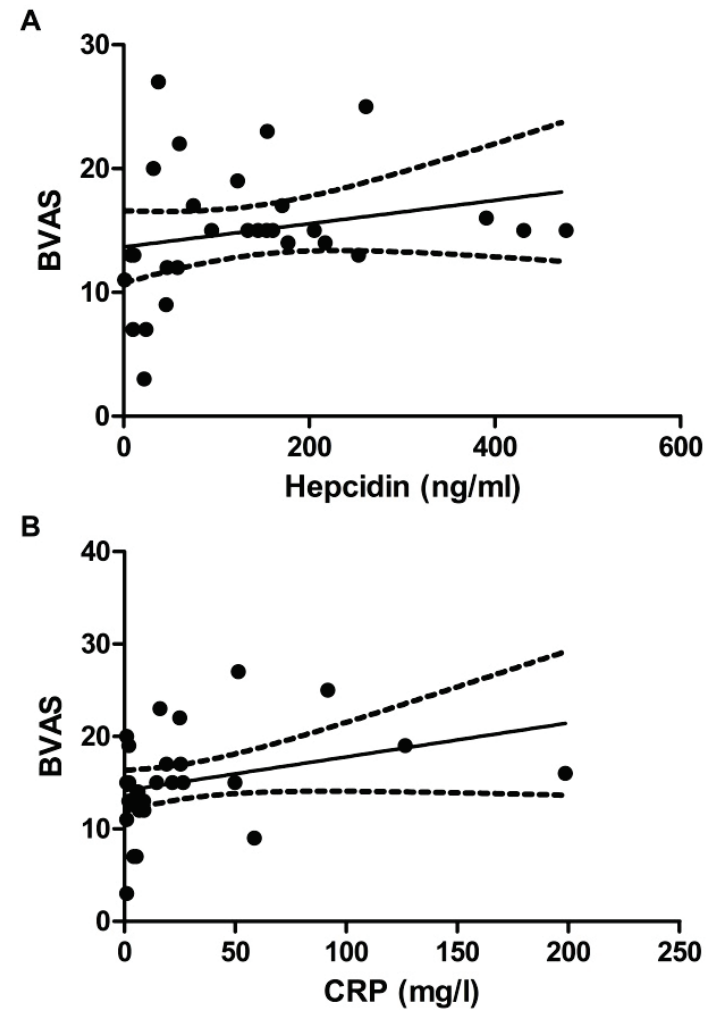

Fig. 3. Correlation of BVAS with hepcidin (A) and CRP (B) in patients with active AAV. A - Spearman $r=0.4298,95 \%$ confidence interval 0.0637 to $0.6939, p=0.0200 ; B$ - Spearman $r=0.4049,95 \%$ confidence interval 0.411 to $0.674, p=0.0264$. 
Table 2. Correlations of serum hepcidin levels in patients with ANCA-associated vasculitis, systemic lupus erythematodes, and patients with end stage kidney disease on hemodialysis.

\begin{tabular}{lccccc}
\hline & Hemoglobin & C-reactive protein & S-ferritine & S-transferrin & S-creatinine \\
\hline Spearman $r$ & -0.2989 & 0.3217 & 0.6223 & -0.4097 & 0.2269 \\
95\% confidence interval & -0.4607 to & 0.1435 to & 0.4927 to & -0.5552 to & 0.04188 to \\
P value & -0.1179 & 0.4797 & 0.7248 & -0.2397 & 0.3969 \\
& 0.0011 & 0.0004 & $<0.0001$ & $<0.0001$ & 0.0139 \\
\hline
\end{tabular}

Table 3. Characteristics of patients with (A) ANCA-associated vasculitis (AAV) and (B) systemic lupus erythematodes (SLE) in remission and with active disease.

\begin{tabular}{|c|c|c|c|}
\hline $\mathbf{A}$ & Remission & Active disease & Statistics \\
\hline Number & 30 & 29 & NS \\
\hline Male/female & $15 / 15$ & $14 / 15$ & NS \\
\hline Age, years & $62.6 \pm 12.6$ & $59.9 \pm 11.7$ & NS \\
\hline Hemoglobin, $g / l$ & $121.6 \pm 18.6$ & $98.6 \pm 13.9$ & $p=0.0001$ \\
\hline S-iron, $\mu \mathrm{mol} / l$ & $16.6 \pm 6.7$ & $12.5 \pm 8.5$ & $p=0.008$ \\
\hline S-ferritin, $\mu g / l$ & $563 \pm 657$ & $461 \pm 388$ & NS \\
\hline$T S A T, \%$ & $34.0 \pm 13.2$ & $34.7 \pm 26.2$ & NS \\
\hline S-transferrin, $g / l$ & $2.28 \pm 0.53$ & $1.77 \pm 0.50$ & $p=0.0003$ \\
\hline S-creatinine, $\mu \mathrm{mol} / \mathrm{l}$ & $223 \pm 131$ & $299 \pm 166$ & $p=0.0288$ \\
\hline$M D R D, \mathrm{ml} / \mathrm{min}$ & $39.5 \pm 29.2$ & $27.5 \pm 30.1$ & $p=0.0362$ \\
\hline Proteinuria, g/24h & $0.39 \pm 0.37$ & $1.45 \pm 3.1$ & $p=0.0006$ \\
\hline ANCA titer & $10.61 \pm 3.81$ & $40.97 \pm 6.42$ & $p<0.0001$ \\
\hline B & Remission & Active disease & Statistics \\
\hline Number & 12 & 17 & NS \\
\hline Male/female & $3 / 9$ & $2 / 15$ & NS \\
\hline Age, years & $41.3 \pm 14.6$ & $37.0 \pm 13.4$ & NS \\
\hline Hemoglobin, g/l & $121.1 \pm 15.9$ & $104.7 \pm 15.3$ & $p=0.0139$ \\
\hline S-iron, $\mu \mathrm{mol} / \mathrm{l}$ & $13.1 \pm 6.3$ & $13.3 \pm 6.2$ & NS \\
\hline S-ferritin, $\mu \mathrm{g} / l$ & $410 \pm 447$ & $359 \pm 366$ & NS \\
\hline$T S A T, \%$ & $26.3 \pm 12.1$ & $31.8 \pm 15.4$ & NS \\
\hline$S$-transferrin, $g / l$ & $2.24 \pm 0.49$ & $1.79 \pm 0.57$ & $p=0.0178$ \\
\hline S-creatinine, $\mu \mathrm{mol} / \mathrm{l}$ & $135 \pm 99$ & $117 \pm 62$ & NS \\
\hline$M D R D, \mathrm{ml} / \mathrm{min}$ & $62.3 \pm 44.0$ & $61.1 \pm 31.6$ & NS \\
\hline Proteinuria, g/24 h & $0.63 \pm 0.94$ & $2.01 \pm 2.45$ & $p=0.0266$ \\
\hline
\end{tabular}

MDRD - glomerular filtration rate calculated by Modification of Diet in Renal Disease equation. Values expressed as mean \pm SD. Statistical analysis by Mann-Whitney test or t-test.

\section{Discussion}

In the present study we evaluated serum hepcidin in 59 patients with the antineutrophil cytoplasmic antibody (ANCA)-associated vasculitides and compared it with healthy controls, blood donors and with patients with lupus nephritis (LN), chronic kidney disease with similar impairment of renal function and 
with end-stage renal disease patients undergoing hemodialysis.

Hepcidin is a key regulator of iron metabolism and can be considered as a final molecule of several physiological and pathological pathways that influence systemic iron metabolism. In clinical situations, it imposes as a biomarker of various situations (Kali et al. 2015, Miseta et al. 2015) that include impaired iron metabolism, anemia and changes in erythropoietic activity, inflammation and compromised renal function. At present, there is a growing amount of information available for these diseases due to the standardization and harmonization of hepcidin measurement (van der Vorm et al. 2016).

New biomarkers are needed to aid the management of AAV (Lally and Spiera 2013) and its activity and are intensively searched for (Ohlsson et al. 2009). ANCA titers are not completely correlated with disease activity and extent of organ involvement (Shuai et al. 2015). Recently, circulating levels of neutrophil extracellular traps (NETs) were not confirmed to be a useful biomarker of the disease activity as well (Wang et al. 2016) while increased levels of NETs remnants were described in patients with active AAV (Soderberg et al. 2015). Hepcidin could serve either as a biomarker of the disease activity, or at least could help to distinguish between renal anemia and ACD. AAV patients with renal involvement usually suffer from both inflammation and impairment of renal function and usually have a degree of anemia which may be a combination of renal anemia and anemia of chronic diseases. Therefore, we correlated hepcidin concentration with parameters of iron metabolism, inflammation, ANCA antibodies, activity of the process and with kidney function.

Hepcidin was significantly increased in patients with AAV, SLE and in patients on HD compared to healthy controls, blood donors and patients with CKD. As these groups had distinct anemia, increased serum ferritin and decreased serum transferrin, hepcidin increase could be related to the presence of inflammation and ACD. However, we are aware of the complex etiology of anemia including the possibility of hemolysis, especially in the active form of SLE or AAV, as well as complex changes during hemodialysis (losses of blood and hemoconcentration during the ultrafiltration). CRP was significantly increased in patients with SLE and AAV, while kidney function was significantly decreased in AAV and HD patients. In the patients with AAV, SLE and in patients with HD hepcidin showed positive correlation with inflammatory parameters (CRP, serum ferritin), decreased renal function (serum creatinine) and negative correlation with hemoglobin and serum transferrin. Thus both the inflammation and renal function impairment could play role in hepcidin increase but hepcidin did not enable to distinguish between these factors.

To study the possible role of hepcidin as an activity marker of the process we divided the patients with SLE and AAV into two groups according to disease activity. In AAV renal function distinctly decreased with the activity of the disease. Hepcidin showed no significant difference between these groups as well as their separate comparison to other studied groups showed the same statistical significance as when considered together. Serum iron was significantly lower in the active form of the disease despite no change of hepcidin. Iron concentration in general is very variable, fluctuating and depends on many factors, including food intake and as a separate parameter has only a limited value even for evaluation of iron deficiency/overload. Serum iron is, apart from inflammation, influenced by many factors like nutrition and nutritional status, gastrointestinal absorption and bleeding. Apart from hepcidin, other inflammatory mechanisms, like nitric oxide, can regulate iron metabolism (Kim and Ponka 2000). Other parameters should be taken into account and in our study hemoglobin and serum transferrin seemed to react better to the activity of the disease. In fact, the serum hepcidin concentration is a result of various counteracting processes. Hepcidin is regulated by other factors than inflammation including iron deficiency and anemia. However, when we considered the patients with active disease, we found statically significant correlation between BVAS and hepcidin and CRP but not with ANCA titer. Hepcidin can be thus considered useful as an additional marker in patients with high BVAS.

In inflammatory diseases serum hepcidin emerges as one of the markers of the activity of these processes (Tan et al. 2012, Zhang et al. 2012) and is as well considered as a pathogenetic factor of anemia of chronic diseases (Huang and Kuo 2017, Masson 2011). However, the number of studies is limited and different methodology of hepcidin measurement makes the conclusions difficult and further studies are needed. This is, at least to our best knowledge, the first study looking at serum hepcidin levels in ANCA-associated renal vasculitis. In other vasculitides, plasma hepcidin was shown to be increased in Kawasaki disease, correlated 
with hemoglobin and decreased after treatment with intravenous immunoglobulins and was suggested as a possible biomarker of this disease (Huang and Kuo 2017, Huang et al. 2016, Huang et al. 2017, Kuo et al. 2012). Serum and saliva hepcidin was also increased in patients with Behcet's disease (Cicek et al. 2013). Similarly to our results, Indrakanti et al. (2017) observed no increase of serum hepcidin in the relation to the increase of renal or extra-renal lupus activity. Increased serum prohepcidin levels were described in patients with rheumatoid arthritis (RA) with no correlation with the disease activity score (Koca et al. 2008), while in another study they reflected the disease activity regardless of the anemia (Kim et al. 2010). Increased serum hepcidin in patients with active RA was a significant predictor of anemia in some studies (Demirag et al. 2009) but in another study serum levels of hepcidin were not different in anemic and non-anemic patients. Treatment of RA patients by tocilizumab improved anemia and led to the reduction of hepcidin levels (Isaacs et al. 2013, Song et al. 2013).

Other studies measured urinary hepcidin (20 and 25 amino acid isoforms) which was suggested to be a biomarker of activity and tubulointerstitial involvement in LN (Zhang et al. 2012), another renal disease characterized by the combination of inflammation, renal impairment and anemia (Zhang et al. 2008). It was shown as a marker of disease activity but was not predictive of renal function loss (Abulaban et al. 2016). Increased urinary hepcidin was also demonstrated to be associated with increased susceptibility to LN (Mohammed et al. 2014). Serum hepcidin was only rarely measured in patients with SLE, but increased serum hepcidin and increased macrophage iron was hypothesized to play a role in the increased risk of myocardial infarction in patients with SLE (Mascitelli et al. 2008).

In conclusion, we found increased serum levels of hepcidin in AAV and SLE that correlated to several laboratory parameters. Hepcidin can thus serve as another marker of the inflammatory process in this disease. Serum hepcidin levels correlated to BVAS in patients with active disease and can thus contribute to the assessment of the activity of the process, especially in combination with other parameters. Longitudinal study with higher number of patients is required to confirm this observation. Furthermore, it remains to be studied whether urinary hepcidin could serve as a marker of tubulointerstitial damage in $\mathrm{AAV}$ in a similar way as in LN.

\section{Conflict of Interest}

There is no conflict of interest.

\section{Acknowledgements}

The study was supported by grant from Czech Health Research Council AZV 15-31662A awarded by the Ministry of Health of the Czech Republic. Institutional support was provided by PRVOUK P24/Progres Q26 from Charles University, Prague, Czech Republic and by RVO-VFN 64165 from General University Hospital, Prague, Czech Republic. Ms. Jana Vávrová, MSc. is acknowledged for technical assistance in introducing the immunological method of hepcidin measurement.

\section{References}

ABULABAN KM, SONG H, ZHANG X, KIMMEL PL, KUSEK JW, NELSON RG, FELDMAN HI, VASAN RS, YING J, MAUER M, NELSESTUEN GL, BENNETT M, BRUNNER HI, ROVIN BH: Predicting decline of kidney function in lupus nephritis using urine biomarkers. Lupus 25: 1012-1018, 2016.

ADDO L, IKUTA K, TANAKA H, TOKI Y, HATAYAMA M, YAMAMOTO M, ITO S, SHINDO M, SASAKI Y, SHIMONAKA Y, FUJIYA M, KOHGO Y: The three isoforms of hepcidin in human serum and their processing determined by liquid chromatography-tandem mass spectrometry (LC-tandem MS). Int J Hematol 103: 34-43, 2016.

AREZES J, NEMETH E: Hepcidin and iron disorders: new biology and clinical approaches. Int J Lab Hematol 37 (Suppl 1): 92-98, 2015.

CASPER C, CHATURVEDI S, MUNSHI N, WONG R, QI M, SCHAFFER M, BANDEKAR R, HALL B, VAN DE VELDE H, VERMEULEN J, REDDY M, VAN RHEE F: analysis of inflammatory and anemia-related biomarkers in a randomized, double-blind, placebo-controlled study of siltuximab (anti-il6 monoclonal antibody) in patients with multicentric Castleman disease. Clin Cancer Res 21: 4294-4304, 2015. 
CICEK D, DAGLI AF, AYDIN S, BASKAYA DOGAN F, DERTLIOGLU SB, UCAK H, DEMIR B: Does hepcidin play a role in the pathogenesis of aphthae in Behcet's disease and recurrent aphthous stomatitis? $J$ Eur Acad Dermatol Venereol 28: 1500-1506, 2013.

DEMIRAG MD, HAZNEDAROGLU S, SANCAK B, KONCA C, GULBAHAR O, OZTURK MA, GOKER B: Circulating hepcidin in the crossroads of anemia and inflammation associated with rheumatoid arthritis. Intern Med 48: 421-426, 2009.

DRAKESMITH H: Next-generation biomarkers for iron status. Nestle Nutr Inst Workshop Ser 84: 59-69, 2016.

GANZ T, NEMETH E: Iron balance and the role of hepcidin in chronic kidney disease. Semin Nephrol 36: 87-93, 2016.

GOMEZ-PUERTA JA, HERNANDEZ-RODRIGUEZ J, LOPEZ-SOTO A, BOSCH X: Antineutrophil cytoplasmic antibody-associated vasculitides and respiratory disease. Chest 136: 1101-1111, 2009.

HAMOUR S, SALAMA AD, PUSEY CD: Management of ANCA-associated vasculitis: current trends and future prospects. Ther Clin Risk Manag 6: 253-264, 2010.

HONDA H, KOBAYASHI Y, ONUMA S, SHIBAGAKI K, YUZA T, HIRAO K, YAMAMOTO T, TOMOSUGI N, SHIBATA T: Associations among erythroferrone and biomarkers of erythropoiesis and iron metabolism, and treatment with long-term erythropoiesis-stimulating agents in patients on hemodialysis. PLoS One 11: e0151601, 2016.

HUANG YH, KUO HC: Anemia in Kawasaki disease: hepcidin as a potential biomarker. Int J Mol Sci 18: E820, 2017.

HUANG YH, KUO HC, HUANG FC, YU HR, HSIEH KS, YANG YL, SHEEN JM, LI SC, KUO HC: Hepcidininduced iron deficiency is related to transient anemia and hypoferremia in Kawasaki disease patients. Int $J \mathrm{Mol}$ Sci 17: E715, 2016.

HUANG YH, YANG KD, HSU YW, LU HF, WONG HS, YU HR, KUO HC, HUANG FC, LO MH, HSIEH KS, CHEN SF, CHANG WC, KUO HC: Correlation of HAMP gene polymorphisms and expression with the susceptibility and length of hospital stays in Taiwanese children with Kawasaki disease. Oncotarget 8: 51859-51868, 2017.

INDRAKANTI DL, ALVARADO A, ZHANG X, BIRMINGHAM DJ, HINTON A, ROVIN BH: The interleukin-6hepcidin-hemoglobin circuit in systemic lupus erythematosus flares. Lupus 26: 200-203, 2017.

ISAACS JD, HARARI O, KOBOLD U, LEE JS, BERNASCONI C: Effect of tocilizumab on haematological markers implicates interleukin-6 signalling in the anaemia of rheumatoid arthritis. Arthritis Res Ther 15: R204, 2013.

KALI A, CHARLES MV, SEETHARAM RS: Hepcidin - a novel biomarker with changing trends. Pharmacogn Rev 9: 35-40, 2015.

KALLENBERG CG: Pathophysiology of ANCA-associated small vessel vasculitis. Curr Rheumatol Rep 12: 399-405, 2010.

KEMNA EH, TJALSMA H, PODUST VN, SWINKELS DW: Mass spectrometry-based hepcidin measurements in serum and urine: analytical aspects and clinical implications. Clin Chem 53: 620-628, 2007.

KIM HR, KIM KW, YOON SY, KIM SH, LEE SH: Serum pro-hepcidin could reflect disease activity in patients with rheumatoid arthritis. J Korean Med Sci 25: 348-352, 2010.

KIM S, PONKA P: Effects of interferon-gamma and lipopolysaccharide on macrophage iron metabolism are mediated by nitric oxide-induced degradation of iron regulatory protein 2.J Biol Chem 275: 6220-6226, 2000.

KOCA SS, ISIK A, USTUNDAG B, METIN K, AKSOY K: Serum pro-hepcidin levels in rheumatoid arthritis and systemic lupus erythematosus. Inflammation 31: 146-153, 2008.

KUO HC, YANG YL, CHUANG JH, TIAO MM, YU HR, HUANG LT, YANG KD, CHANG WC, LEE CP, HUANG YH: Inflammation-induced hepcidin is associated with the development of anemia and coronary artery lesions in Kawasaki disease. J Clin Immunol 32: 746-752, 2012.

LAARAKKERS CM, WIEGERINCK ET, KLAVER S, KOLODZIEJCZYK M, GILLE H, HOHLBAUM AM, TJALSMA H, SWINKELS DW: Improved mass spectrometry assay for plasma hepcidin: detection and characterization of a novel hepcidin isoform. PLoS One 8: e75518, 2013.

LALLY L, SPIERA RF: Biomarkers in ANCA-associated vasculitis. Curr Rheumatol Rep 15: 363, 2013.

MACDOUGALL IC, MALYSZKO J, HIDER RC, BANSAL SS: Current status of the measurement of blood hepcidin levels in chronic kidney disease. Clin J Am Soc Nephrol 5: 1681-1689, 2010. 
MARUNA P, VOKURKA M, LINDNER J: Plasma hepcidin correlates positively with interleukin-6 in patients undergoing pulmonary endarterectomy. Physiol Res 60: 493-502, 2011.

MASCITELLI L, PEZZETTA F, SULLIVAN JL: Iron, hepcidin, and increased atherosclerosis in systemic lupus erythematosus. Int J Cardiol 131: e20-e21, 2008.

MASSON C: Rheumatoid anemia. Joint Bone Spine 78: 131-137, 2011.

MISETA A, NAGY J, NAGY T, POOR VS, FEKETE Z, SIPOS K: Hepcidin and its potential clinical utility. Cell Biol Int 39: 1191-1202, 2015.

MOHAMMED MF, BELAL D, BAKRY S, MARIE MA, RASHED L, ELDIN RE, EL-HAMID SA: A study of hepcidin and monocyte chemoattractant protein-1 in Egyptian females with systemic lupus erythematosus. J Clin Lab Anal 28: 306-309, 2014.

NEMETH E, VALORE EV, TERRITO M, SCHILlER G, LICHTENSTEIN A, GANZ T: Hepcidin, a putative mediator of anemia of inflammation, is a type II acute-phase protein. Blood 101: 2461-2463, 2003.

OHLSSON S, BAKOUSH O, TENCER J, TORFFVIT O, SEGELMARK M: Monocyte chemoattractant protein 1 is a prognostic marker in ANCA-associated small vessel vasculitis. Mediators Inflamm 2009: 584916, 2009.

RISHI G, WALLACE DF, SUBRAMANIAM VN: Hepcidin: regulation of the master iron regulator. Biosci Rep 35 : $\mathrm{e} 00192,2015$.

SHUAI ZW, LV YF, ZHANG MM, HU ZY: Clinical analysis of patients with myeloperoxidase antineutrophil cytoplasmic antibody-associated vasculitis. Genet Mol Res 14: 5296-5303, 2015.

SODERBERG D, KURZ T, MOTAMEDI A, HELLMARK T, ERIKSSON P, SEGELMARK M: Increased levels of neutrophil extracellular trap remnants in the circulation of patients with small vessel vasculitis, but an inverse correlation to anti-neutrophil cytoplasmic antibodies during remission. Rheumatology (Oxford) 54: 2085-2094, 2015.

SONG SN, IWAHASHI M, TOMOSUGI N, UNO K, YAMANA J, YAMANA S, ISOBE T, ITO H, KAWABATA H, YOSHIZAKI K: Comparative evaluation of the effects of treatment with tocilizumab and TNF-alpha inhibitors on serum hepcidin, anemia response and disease activity in rheumatoid arthritis patients. Arthritis Res Ther 15: R141, 2013.

TALARICO R, BALDINI C, DELLA ROSSA A, CARLI L, TANI C, BOMBARDIERI S: Systemic vasculitis: a critical digest of the recent literature. Clin Exp Rheumatol 31 (Suppl 75): S84-S88, 2013.

TAN TC, CRAWFORD DH, FRANKLIN ME, JASKOWSKI LA, MACDONALD GA, JONSSON JR, WATSON MJ, TAYLOR PJ, FLETCHER LM: The serum hepcidin:ferritin ratio is a potential biomarker for cirrhosis. Liver Int 32: 1391-1399, 2012.

TESAR V, HRUSKOVA Z: ANCA-associated renal vasculitis - an update. Contrib Nephrol 181: 216-228, 2013.

TROUTT JS, BUTTERFIELD AM, KONRAD RJ: Hepcidin-25 concentrations are markedly increased in patients with chronic kidney disease and are inversely correlated with estimated glomerular filtration rates. J Clin Lab Anal 27: 504-510, 2013.

VAN DER VORM LN, HENDRIKS JC, LAARAKKERS CM, KLAVER S, ARMITAGE AE, BAMBERG A, GEURTS-MOESPOT AJ, GIRELLI D, HERKERT M, ITKONEN O, KONRAD RJ, TOMOSUGI N, WESTERMAN M, BANSAL SS, CAMPOSTRINI N, DRAKESMITH H, FILLET M, OLBINA G, PASRICHA SR, PITTS KR, SLOAN JH, TAGLIARO F, WEYKAMP CW, SWINKELS DW: Toward worldwide hepcidin assay harmonization: identification of a commutable secondary reference material. Clin Chem 62: 993-1001, 2016.

VOKURKA M, KRIJT J, SULC K, NECAS E: Hepcidin mRNA levels in mouse liver respond to inhibition of erythropoiesis. Physiol Res 55: 667-674, 2006.

WANG CY, BABITT JL: Hepcidin regulation in the anemia of inflammation. Curr Opin Hematol 23: 189-197, 2016.

WANG H, SHA LL, MA TT, ZHANG LX, CHEN M, ZHAO MH: Circulating level of neutrophil extracellular traps is not a useful biomarker for assessing disease activity in antineutrophil cytoplasmic antibody-associated vasculitis. PLoS One 11: e0148197, 2016.

WEISS G: Iron metabolism in the anemia of chronic disease. Biochim Biophys Acta 1790: 682-693, 2009. 
ZHANG X, JIN M, WU H, NADASDY T, NADASDY G, HARRIS N, GREEN-CHURCH K, NAGARAJA H, BIRMINGHAM DJ, YU CY, HEBERT LA, ROVIN BH: Biomarkers of lupus nephritis determined by serial urine proteomics. Kidney Int 74: 799-807, 2008.

ZHANG X, NAGARAJA HN, NADASDY T, SONG H, MCKINLEY A, PROSEK J, KAMADANA S, ROVIN BH: A composite urine biomarker reflects interstitial inflammation in lupus nephritis kidney biopsies. Kidney Int 81: 401-406, 2012. 